\title{
AC 2007-2260: A SUCCESSFUL PROFESSIONAL DEVELOPMENT ACTIVITY TO INFUSE ENGINEERING CONTENT FOR UTAH 9-12 TEACHERS
}

\section{Steve Shumway, Brigham Young University}

Steven Shumway is an Associate Professor and Program Chair for the Technology Teacher

Education Program in the School of Technology, Ira A. Fulton College of Engineering and Technology, at Brigham Young University in Provo, Utah. Before joining BYU, Steve was a highly successful high school technology education teacher. He is one of BYU's co-investigators for the National Science Foundation (NSF) funded National Center for Engineering and Technology Education (NCETE).

\section{Jared Berrett, Brigham Young University}

Having obtained a Bachelors of Science degree with a dual major in Psychology and Technology from Brigham Young University, Jared decided to pursue a career in understanding teaching, learning, and technology. He began teaching for three different public high schools in Utah while he finished a Masters degree in Technology Teacher Education. He worked for two major IT corporations and also spent a year as a project management consultant in the IT field before he chose to pursue a $\mathrm{PhD}$ from the University of Illinois Urbana-Champaign. At Illinois, he coordinated an online masters degree program, was an NSF sponsored technology trainee, and consulted with faculty from the College of Engineering and College of Education to improve their teaching and use of technology. He has been involved in numerous projects in industry focusing on topics such as: emotional intelligence, entrepreneurship, and improving and evaluating productivity and the needs of high-tech start-ups. His $\mathrm{PhD}$ is in Education with an emphasis in the psychology of learning and technology. He currently is a faculty member at Brigham Young University in the Technology Teacher Education program where he teaches heavily, consults, serves as the Graduate Coordinator, and mentors numerous graduate and undergraduate students in research projects. He is happily married, has 6 children, and loves to learn. His research interests include technological literacy for a global society of change and advancement, and teaching and learning practices that promote higher order thinking skills and creativity. He is comfortable in all settings of teaching and learning from public classrooms to corporate boardrooms.

\section{Andy Swapp, Milford High School}

After retiring from a great career as an Infantry Sergeant in the U.S. Army in 1996, Andy graduated with honors from Southern Utah University with a BS degree in Technology education. He became a Career and Technology education teacher at Milford High School in the Beaver County school district and a small farm owner in the year 2001. He has been innovating a new renewable energy class under the guise of Advanced Technology. He consults on the side for the UPC wind development group.

\section{Ronald Terry, Brigham Young University}

Ron is a Professor of Chemical Engineering at Brigham Young University and an Associate in BYU's Office of Planning and Assessment. His scholarship centers on pedagogy, student learning, and engineering ethics and has presented/published numerous articles in engineering education. He is one of BYU's co-investigators for the NSF funded NCETE.

\section{Thomas Erekson, Western Illinois University}

Dr. Erekson serves as the Dean for the College of Business and Technology at Western Illinois University. Prior to moving to WIU in June 2006, he served as the Director for the School of Technology, a unit in the College of Engineering and Technology at Brigham Young University. He has published more than 60 articles, two books, and has presented more than 100 papers at national conferences. Dr. Erekson was instrumental in securing NSF funding for NCETE, a 
Center for Learning and Teaching. The NCETE's focus is to infuse engineering design and analytical methods into K-12 schools through technology education by linking engineering faculty and technology education faculty at nine leading universities. 


\title{
A Successful Professional Development Activity to Infuse Engineering Content for Utah 9-12 Teachers
}

\author{
Steven Shumway, Jared Berrett, Andrew G Swapp, \\ Thomas L. Erekson, and Ronald E. Terry
}

\begin{abstract}
As part of the National Science Foundation funded National Center for Engineering and Technology Education (NCETE), faculty at Brigham Young University have been conducting professional development activities for Utah 9-12 grade teachers.

The paper discusses two years of professional development activities. Lessons learned from the first year helped build a successful activity that the second-year participants found to be extremely engaging. The paper discusses these lessons learned and reports on how the teachers are implementing the content of the professional development in their courses. A model for engineering design using a problem-solving cycle developed at Dartmouth was taught to the 9-12 grade teachers to help infuse engineering design content in their courses. Specific examples are provided in the paper of how one of the teachers has used the problem-solving cycle in his high school classes.
\end{abstract}

A key-activity during the second-year professional development was the use of a capstone-like project. This project was to build an electrically powered vehicle to be used in the Electrathon America competition. The participants used the problem-solving cycle to help design and build the vehicle.

\section{Introduction}

The National Center for Engineering and Technology Education (NCETE) is one of 17 National Science Foundation (NSF) funded Centers for Learning and Teaching. It is the only one of the 17 addressing engineering and technology education. The ultimate goal of the center is to infuse engineering design, problem solving, and analytical skills into the K-12 schools. NCETE is made up of 9 partner universities, one of which is Brigham Young University (BYU), Provo, Utah. As part of NCETE, BYU and 4 other partner institutions are responsible to conduct professional development activities for K-12 teachers. The goals of the professional development effort are to:

- develop teachers' instructional decision making so that it focuses on the analytical nature of design and problem solving needed to deliver technological as well as engineering concepts.

- facilitate teacher initiated change in program design, curricular choices, programmatic and student assessment, and other areas that will impact learning related to technology and engineering.

- develop teachers' capabilities as learners so that they assume leadership for their professional development activities, and recruit and mentor their colleagues. 
- create a pool of highly skilled cooperating teachers who will accept pre-service technology teachers into their classrooms and mentor the next generation of technology/engineering teachers to effectively teach students of diverse backgrounds.

- develop engineering analysis and design skills in technology teachers, and to strengthen their mathematics and science knowledge and skills.

- develop curriculum integration and collaboration skills in practicing technology teachers so that they can effectively collaborate with mathematics and science teachers.

This paper will document the first two years of professional development activities conducted by BYU faculty.

\section{Professional Development Literature Review}

Because of the potential impact on the quality of teaching and learning that occurs in the classroom, there has been a considerable amount of research conducted on the topic of professional development in the last 20-30 years. From these primary research studies and related meta-analyses, many effective methods for conducting professional development have been identified. The incorporation of these "best practices" is imperative in developing effective professional development and in realizing the goal of the center to infuse engineering design, problem solving, and analytical skills into the K-12 schools.

When considering participants for professional development, Wade, in a meta-analysis of 91 research studies found that professional development activities are most successful when participants are chosen by their leaders or colleagues to attend or that they are selected on some type of competitive basis. ${ }^{1}$ In addition, professional development participants should be provided with some type of special recognition for their involvement.

Locke comments that professional development programs are most successful when the participants are involved in the planning process. ${ }^{2}$ This aspect of professional development is often overlooked as it is much easier for the deliverers of professional development to pre-plan activities rather than plan activities in collaboration with participants. Despite the effectiveness of this collaboration, Wade found that professional development is more effective when the leader then assumes the primary role of the "presenter" of information and the participants are "receivers". 1

From their meta-analysis of almost 200 research studies, Showers, Joyce, \& Bennett found that in order for classroom teachers to successfully transform the information from professional development sessions back into their classrooms the professional development component should include four parts: 1) presentation of theory, 2) demonstration of a new strategy, 3) initial practice, and 4) prompt feedback about their efforts. ${ }^{3}$ Additionally important, Showers et. al. also found that teachers are more likely to use new strategies if they receive coaching while they are trying to use the strategies in their classrooms.

Regarding the length and timing of professional development, Korinek, Schmid, and McAdams found that professional development should be offered at times that are convenient for participants and that in general, "single shot" inservice activities are not effective. ${ }^{4}$ Related to 
this, is the finding by Wade that teachers are more likely to benefit from professional development when they have time to review and incorporate the concepts learned on their own. ${ }^{1}$ Finally, one of the strongest research findings is that professional development programs are most effective if the concepts to be learned meet the local needs of the participants and then if the teachers are allowed to make a concrete application of these concepts in their classroom and that long-term assistance be provided related to professional development material (Berman \& McLaughlin). ${ }^{5}$

\section{Professional Development - Year One (2005)}

The first year professional development was designed by the NCETE BYU team in the fall of 2004. The framework for the professional development, as identified below, was shaped by the previously listed goals and from known best practices of professional development as identified in professional development research and related literature. This framework included the following:

1. The professional development program was to include eight full day sessions during the spring semester (two days per month for four months) and a one week capstone experience in the summer (approximately 100 clock hours of professional development).

2. The project would provide a stipend to each teacher participating, and would cover travel expenses and substitute teacher costs for the participants to attend sessions during the school year.

3. Administrators in the three NCETE partner school districts in Utah (Davis, Jordan, and Wasatch) were contacted to identify five technology education teachers to participate in the program.

4. An application form was developed and completed by interested teachers.

5. A detailed program outline was developed by the NCETE BYU team, including engineering updates (tours of engineering research labs), lecture/discussion sessions, and hands-on sessions.

6. Evaluation instruments were developed and administered after each session to provide formative evaluation. A summative evaluation form was also developed and administered.

Five teachers applied for and were admitted to the engineering professional development program, however, one teacher withdrew at the last minute due to personal reasons. The four remaining teachers included two high school technology education teachers, one high school drafting teacher, and one large district coordinator for technology education. The two technology education teachers and the district coordinator each had 15-20 years of classroom experience teaching technology subjects while the drafting teacher had been teaching for 9 years. Each of these teachers graduated from an Industrial Arts/Technology Education teacher preparation program and while none were currently teaching pre-engineering subjects, each was interested in doing so in the future.

The program schedule was finalized at the first session with all participants. It was difficult to set the schedule given the array of school responsibilities the teachers had (e.g., coaching 
softball, advising TSA). In addition, the teachers were concerned about being out of their classrooms/laboratories for eight days in their spring semester.

Each of the eight one-day sessions began with a tour of various engineering research labs at BYU, including the virtual reality theater, friction stir welding research, Iso-Truss research lab, and the Electric Vehicle Research Lab. Exposing the technology teachers to the latest engineering research was rated very high by the teachers.

The professional development lecture/discussion sessions focused on the engineering profession, engineering design, and the Standards for Technological Literacy. ${ }^{6}$ Approximately half way through the spring semester, two BYU team members visited the teachers in their schools. These visits were designed to expose the BYU team's engineering faculty member to technology education and to do a qualitative formative assessment of the program to date. As a result of these visits, the program was modified in an attempt to target the activities to those that the teachers could easily implement in their classrooms. Of course, adapting the program to meet the needs for each technology teacher was difficult given the range of courses each taught (no teachers taught the same array of courses). One area of success was in the area of 3-D CAD as two teachers were planning to purchase packages for the upcoming year. The drafting teacher was able to conduct a hands-on session on the use of 3-D CAD for the participants. He, however, had not used the finite element analysis component of the CAD software, and the BYU team was able to add to his knowledge with specific FEA training.

The summer session was originally intended to be a capstone-type design experience. However, based on the formative assessment and our struggle to engage the diverse interests of the cohort, the summer program focused on systems control. The technology teachers had previously identified systems control as an area of expertise that they needed and could use in their classrooms.

Near the end of the summer of 2005, the BYU team met to reflectively assess the strengths and weaknesses of the program as we prepared for the next round of professional development. Our assessment was that we successfully followed the model of 1) presentation of theory, 2) demonstration of a new strategy, 3) initial practice, and 4) prompt feedback about participant's efforts. However, despite a successful incorporation of many of the "best practices" (competitive selection of participants, allowing participants to participate in the planning, professional development over an extended period of time) we did not fully realize other best practices. For example, while participants were generally interested in the content of the summer workshop, the content did not meet the local needs of the participants and thus the teachers did not make a concrete application of these concepts into their classroom and thus no long-term assistance was given related to professional development. Our basic assessment was that we had strayed from our original intent in an attempt to meet specific teacher needs. In fact, because the participants had such diverse teaching responsibilities, their needs were varied and difficult to address in the professional development. However, the comments from the teachers regarding the professional development were generally positive and teachers expressed a desire to incorporate the concepts learned into their classrooms in the future. The general consensus from the BYU group was that for the next cohort we should select a more homogenous group of teachers and stick to our plan. 


\section{Professional Development - Year Two (2006)}

After the summer planning meeting and reviewing the professional development of 2005 with the first cohort of teachers, the following goals were developed for the 2006 cohort:

1. To expose the teachers to the engineering profession, its scope and its methods by teaching about the profession and arranging field trips to engineering firms and visits to engineering research labs at universities.

2. To immerse the teachers in the engineering design process by using an array of engineering design and problem solving activities; providing appropriate books, support materials, and examples of engineering curriculum that is age appropriate for 7-12 students; using selected engineering case studies; and providing a one-week, summer capstone engineering design activity.

3. To expose the participants to the engineering design process in a hands-on activity that could be modeled at the professional development workshops and implemented in the high school engineering curriculum.

4. To guide the teachers in developing at least one unit designed to infuse engineering design and problem solving into the courses they teach.

The BYU NCETE group participated in two significant activities in the summer and fall of 2005 that provided additional direction for the 2006 professional development. The first involved participation in a professional development activity that was sponsored by the Boston Museum of Science and subsequent exposure to a Dartmouth engineering program designed for K-12 teacher professional development. One of the key components of the Dartmouth engineering program that was so enticing to the BYU group was the introduction and emphasis of a problemsolving cycle and accompanying decision matrix. ${ }^{7}$ It was hoped that the incorporation of the Dartmouth model would allow the high school teachers that were participants in the professional development, and thus ultimately their students, to approach engineering problems using a structured and systematic process rather than a trial and error approach common in many technology education classrooms. In addition, this approach would allow students of all grade level and abilities to solve problems rather than only students with advanced mathematics and science skills.

This problem-solving cycle, while similar to other approaches to engineering design, allows the user to:

1. look at the problem carefully,

2. redefine the problem to eliminate bias,

3. identify constraints and set specifications for solutions,

4. brainstorm alternative solutions,

5. analyze the alternatives with the decision matrix,

6. select the best potential solution and test it,

7. look at the original problem statement and decide whether or not the problem has been solved 
(Note: A problem-solving cycle graphic representing the Dartmouth model, which is copyrighted, can be found online at http://engineering.dartmouth.edu/teps/images/ch1.pdf).

The key to analysis in this problem-solving cycle is step 5 and the use of the decision matrix. In the matrix, the columns are headed by a list of specifications and the rows represent the ideas for alternative solutions. Alternatives can be ranked using a simple scale such as good, bad or neutral or even a more sophisticated weighted scale. The students would perform research, collect data and even conduct mathematical models or simulations that would allow them to evaluate each alternative according to the specifications and then the alternative with the highest score would become the solution to the problem. This problem-solving cycle, with accompanying decision matrix was to become one of the key components for the professional development content that would be taught to the teachers. This approach to the analysis portion of the problem-solving cycle allows K-12 teachers to use appropriate grade-level mathematics and allows a teacher in any grade to implement the cycle.

The second significant planning activity was a meeting with Melvin Robinson, Technology and Engineering Education Specialist for the Utah State Office of Education, to discuss the successes and challenges of the 2006 professional development activities. His advice was also sought to identify a cohort of teachers that would have a common interest and application. In doing this we hoped to avoid some of the problems experienced in year one. He suggested a group of teachers that were implementing, or were planning to implement, the Utah Pre-engineering Pathway to satisfy the Utah Career and Technical Education requirement. It was decided to concentrate on high school teachers from rural communities that were implementing the Utah Plan, or were planning to implement it within a year. This would narrow the focus of the professional development as the participants would be teaching similar courses, and would be more motivated. In addition, from the meeting with Robinson, it was decided to use the Electrathon competition as the capstone design activity. Robinson had plans to sponsor an Electrathon competition in Utah, but to date had lacked the time and resources to get it off the ground. The choice of this activity was also facilitated by the knowledge that one of the doctoral students, an NCETE Fellow at Utah State University, had extensive experience with the design and construction of Electrathon vehicles in rural high schools. He proved instrumental in helping assure the success of the activity.

The following design elements for the 2006 professional development were identified from these meetings and the lessons learned from the 2005 activities:

- BYU's efforts would focus on professional development for teachers, and techniques to infuse engineering design and problem solving, in rural and small school settings.

- BYU's efforts would dovetail with and promoted the Utah Pre-engineering Pathway for meeting the Utah Career and Technical Education requirement.

- BYU's efforts would test a format that utilizes four two-day sessions during the school year (using a Friday/Saturday format to reduce travel and time away from school for the teachers) combined with a one-week full-time session during the summer. 
- Most of the four two-day spring sessions were to be conducted off campus in small school settings, testing the delivery of professional development in the more rural parts of the state.

- The Dartmouth problem-solving cycle would form the basis for introducing the engineering design process.

- The Electrathon car competition would form the basis for the capstone design process and be used as a framework for structuring content lectures/presentations/discussions throughout the sessions giving the participants cognitive scaffolding and contextual applications of the knowledge they were receiving.

The 2006 cohort included five teachers, four were teaching the Utah Plan for engineering and the fifth was planning to teach it starting fall of 2006. Interestingly, four of these teachers entered the technology education profession through an alternative licensure program after many years of industry experience. The fifth teacher was a science teacher that had received an additional endorsement to teach a technology education course. Each of these teachers had between 5-10 years of teaching experience. Given the rural nature of the schools, the cohort teachers were teaching an array of science and technology subjects in addition to the Utah Engineering Plan course. The science background of the cohort enhanced the professional development. The majority of the teachers were from southwestern Utah and the spring workshop sessions for this cohort were delivered at three different high schools in southwestern Utah.

One of our concerns identified in planning the professional development was finding cutting edge engineering tours in rural Utah. This concern did not materialize as a problem as we had tours of an experimental bio-fuels facility (methanol production) and the new integrated engineering program and labs at Southern Utah University.

Using a central project - the engineering design and construction of an Electrathon vehicle provided a focus and coherence for the total professional development program. In the spring two-day sessions the content focused on the design and engineering of the vehicle. The participants used the Dartmouth problem-solving cycle and decision matrix for analysis of components. This model is flexible regarding the amount and degree of mathematics that is incorporated by the user. In our case, it provided an analytical approach that can be used with high school students who have limited mathematic capabilities. The participants were assigned "homework" (aspects of design for the project) at the end of each session. They eagerly brought solutions to the next session all geared toward the development of the car.

The final two-day session and the week long capstone were conducted on campus at BYU. The two-day session was the final design phase and the week long session was to actually construct a working prototype. The prototype was to be available for use by the teachers in the fall to motivate their students as they taught engineering design under the Utah Plan. The prototype was also to be made available to Melvin Robinson to encourage other teachers in Utah to consider participating in an Electrathon competition. 
The 2006 program was significantly more successful than the 2005 program as indicated by results of a participant survey discussed below. All of the 2006 participants were teaching engineering design, using the Dartmouth problem-solving cycle, and their students were designing Electrathon vehicles in the 2006-07 school year.

\section{Evaluation: Survey of Participants}

A brief survey was developed in the fall of 2006 to assist in determining the participants' satisfaction concerning the professional development and the degree to which they had implemented it in the classroom. The survey involved both questions using a 4-point Likertscale and questions that were opened-ended. The sample size was obviously small especially considering that not all of the participants returned their completed surveys. Two of the 4 first year participants and 4 of the 5 second year participants responded to the survey. In the Likertscale questions, all of the averages of the responses indicated either the same or higher satisfaction for the second year responders. The open-ended questions provided some interesting comments, particularly from the Year 2 participants and their attempts to incorporate the Dartmouth problem-solving cycle and the use of the decision matrix in their teaching. The following comments were made by the Year 2 participants:

Question: In what ways have you used the knowledge you gained in the PD (professional development) in your classroom?

- I have used the decision making matrix the most. The matrix makes life's decisions much easier. Students who grasp the concept use it in everyday life. In the classroom we make decisions like what kind of materials to use for our mini wind turbine blades, what gauge wire to make windings out of for our permanent magnet alternators. The list goes on. The problem solving cycle has been a great teaching tool also.

- The problem solving matrix was a great tool to get the students to try to start thinking.

- I've used the videos, the matrix and design of the eCar for the purpose of teaching pre-engineering.

- I have had a lot more success in getting to student to judge (and select) work with an open mind using the matrix.

Question: In what ways have you seen students benefit from the PD experience?

- Engineering is not a foreign thing that makes students stand back and look at you with fear in their eyes. When I describe people who can identify a problem and solve it students seem to take notice and realize that engineering may be something interesting and useful.

- The pedagogical information and implementation was necessary for me personally. The team skills are good ice breakers as well as critical thinking practices. They really enjoyed the Lego castle. I even made it more complex. 
- It's been good to see the students go through the same experiences that we went through as teachers. It's interesting that they have had most of the same problems, and in some cases have been more successful than we were.

- Better problem solvers and able to apply concepts to outside situations.

Question: Do you think your students understand more about engineering because of the PD efforts? If so, how do you know?

- YES. I know they do because I had a hard time explaining exactly what engineers did before the PD, now I have a much better grasp on the many different aspects of engineering, but basically engineers identify problems and solve them. My students undoubtedly know this now because I have them practice this in almost every class I teach.

- Yes, because I have a better understanding of how to deliver the material for them.

- Their understanding is a hard thing to measure through this process. I have seen them trouble shoot and design the eCar in many of the same ways we would as engineers.

- Yes, I have more information to share with them.

Question: Do you think your students are better problem solvers because of the PD efforts? If so, how do you know?

- Before the PD if I had a student who needed to make a decision on which type of materials would be best for the job I would ask them a few questions and make a suggestion as to what material would be the best. Now I ask them to list the specifications that are most important to them and then list possible materials that could be used (matrix time). The matrix is absolutely the neatest thing to use! On rare occasion my advice has been overruled by the matrix.

- I don't know if they are better at solving problems. It seems as though the students are almost incapable of any autonomous thoughts, or maybe it's just the students I happen to get in the class. Perhaps other critical thinking skills beyond the matrices could be incorporated into the PD.

- Definitely, maybe its because of the caliber of student I have in my class, but they seem not wanting help but unwilling to ask a teacher for that help; they want to solve it on their own.

- Yes.

Question: In what ways have you seen students use it (problem-solving cycle) in their personal lives?

- One student was shopping for a used truck. He is a diehard Chevy man who is now driving a Dodge. The matrix was weighted heavily as far as the brand was concerned, but knowing the previous owner was weighted very heavily also.

- I really haven't. I can't get them to do any homework, let alone use anything from the class once the bell rings.

- I don't have them in any other class therefore its hard to measure.

- No comment. 
Question: In what ways have you used it (problem-solving cycle) in your personal life?

- Deciding which animals are best for my farm. Which crops to plant. Guiding my own children into career exploration. Knowing a lot more about engineering and technology makes it easier to explain things to my own children as well as my students. Personally I always wanted to be a good old shop teacher and I fought being called a tech ed teacher. I did not like being confused with the computer teacher. Now I enjoy being called a Tech Ed Teacher.

- I have always used the problem solving matrix in my personal life, but I have gone through the steps in my mind automatically. I did not know about the physical structure of the matrix, which is a good tool to expose the students to. I did however, introduce the matrix to my wife to help her decide which of two cars to sell and which one to keep. I often use her as a guinea pig before I try an idea with the students.

- None really, other than what I've already tried to incorporate.

- No comment.

From these responses, it is apparent that the Year 2 participants were influenced by the Dartmouth problem-solving cycle and decision matrix, and they attempted to use it in their teaching. The Year 1 responses to the same questions did not include any attempts to include any of the Year 1 professional development material in the classroom with the exception of the 3-D CAD material.

\section{Summary and Conclusions}

Based on the experience with and evaluation of the two cohorts, we have concluded that effective professional development programs can be developed and delivered to technology teachers to empower them to infuse engineering design and analytical methods into K-12 schools. Based on the literature, and the BYU experience, engineering professional development for K-12 teachers is more effective when it:

- is grounded in the literature,

- links with state and local curriculum efforts,

- obtains support from state and local education administrators,

- mixes theory with authentic practice,

- involves effective K-12 teachers in its design and delivery,

- uses an engineering problem-solving process that involves an analysis component that can be applied at any grade level,

- provides context for learning and applying math and science,

- is directly applicable to the $\mathrm{K}-12$ classroom/lab settings,

- requires the teachers to immediately practice what they are taught,

- provides feedback from the professional development instructors to the teachers on their practice,

- contains an assessment process that not only assesses the teachers but their students after implementation of the professional development ideas. 


\section{End Note}

After seeing the success of the Dartmouth model, one of the BYU faculty members has incorporated it in an ongoing K-12 engineering research effort during an academic leave in 2006/2007. He notes the following:

In 2006 I began teaching a new engineering class to introduce engineering and technology to students in a rural 9-12 public high school in southeastern Utah. The community was very excited to have the new offering and 12 students out of 400 in the school initially joined. One of the key research questions I wanted to address in my teaching was how to create excitement about engineering as a fun career while considering the perceived need for more math and scientific rigor in the curriculum. Based on the success we had in the professional development of high school teachers, I decided to follow the pedagogy of having a design challenge as a framework to introduce key engineering concepts. We have been using an electrathon car and have entered the FIRST engineering robotics competition. Though I have learned that I should not have two such big projects going on simultaneously in a first year class, these events have served as an amazing catalyst and framework for learning about systems, project management, business planning, innovation, team work, etc. The math quite frankly has taken second seat to more transferable skills.

The Dartmouth model to problem-solving in particular has been a great model which provides flexibility but intellectual rigor and a structure to a very complex process. The first time I asked students to come up with a design for the electrathon car, we began with two days of research to look at the problem carefully. Then we met and wrote up our understandings with constraints and specifications for solutions. We came up with alternative ideas and the students immediately came up with a solution. As I inquired about their supposed "best" solution, I asked what criteria they used to come up with it. They couldn't say specifically - it just seemed like the best idea based on opinion. By introducing the decision matrix, students were able to go back through and critique their ideas and defend their solutions. The design of our car actually changed from the initial "best" concept when complete and we are well on our way to prototyping it.

One of our Year 2 teachers had the following additional comments regarding the implementation of the problem-solving cycle, particularly the decision matrix.

Use of the Matrix has turned the decision making process into a quantifiable scientific process that will eliminate or allow for certain prejudice depending on the use of a weighted system or not. For example in choosing a material for a project certain students will always gravitate towards woods or metal because they are comfortable and familiar with these materials. When a composite, or other unfamiliar material, is mentioned for use on a project doubt of its strength, workability, and durability are of great concern and usually the unfamiliar and often superior material is passed over. With a little research, expert advice, and experimentation, students learn of the workability and durability of the unfamiliar material. Prejudice will still guide the decision making process of which material is the best for the given project. The decision-making matrix is devised to take most of the prejudice out and make the wise decision. Students will list the possible materials to be used and then list the specifications that are desirable. The information is 
plugged into the matrix and value is assigned to each specification of each material. The end result when all the numbers are added is usually the best material for the job.

Students using the matrix, and believing the result, do not have the trial and error cycles to go through that the student who chooses the non-scientific method. A great example of this is with our mini-wind turbine blade design contest. Students need to design and build a set of blades that will attach to a small DC motor and when placed in front of a box type fan will spin the motor producing electricity. The blades that spin the motor the fastest will produce the most electricity. The materials that are usually available are Styrofoam, Balsa wood, Bass wood and sheet metal. The material needs to be light, strong, and durable. I have observed students choosing material that they are most comfortable working with and hoping that it is the best choice. The matrix helps students to see that two of these materials are far superior for this particular challenge and for the set time constraints.

I am pleased as well as excited about the time and material savings that the matrix affords our classes. The trial and error method still exists, mostly due to stubbornness, but when students see how engineers using this method can save time and $\$ \$ \$$ it sends home a great message about the validity of this process.

I have started my eighth graders on this method and I will monitor them until they graduate. I feel sure that with regular practice I will see the matrix used like it was second nature by time these students leave MHS. I am looking to collaborate with the math and science teachers in the near future and see if they can implement this in their curriculum also.

\section{References}

1. Wade, R.K. (December 1984/January 1985). What makes a difference in inservice teacher education? A metaanalysis of research. Educational Leadership, 42, 48-54

2. Locke, W.E., Teacher attitudes suggest inservice programs, (ERIC Document Reproduction Service No. ED $283785,1985)$.

3. Showers, B., Joyce, B., \& Bennett, B., Synthesis of research on staff development: A framework for future study and a state-of-the-art analysis. Educational Leadership, 77-87, November 1987.

4. Korinek, L., Schmid, R., \& McAdams, M., Inservice Types and Best Practices, Journal of Research and Development in Education, 18(2), 33-38, 1985.

5. Berman, P., \& McLaughlin, M., Federal programs supporting educational change, Vol IV: The findings in Review. Santa Monica, CA: Rand Corporation, 1974.

6. Standards for Technological Literacy, ITEA, 2000.

7. Frye, E., Engineering Problem Solving for Mathematics, Science, and Technology Education. Hanover, NH: Thayer School of Engineering, Dartmouth College, 1996. 


\section{Steven Shumway}

Steven Shumway is an Associate Professor and Program Chair for the Technology Teacher Education Program in the School of Technology, Ira A. Fulton College of Engineering and Technology, at Brigham Young University in Provo, Utah. Before joining BYU, Steve was a highly successful high school technology education teacher. He is one of BYU's coinvestigators for the National Science Foundation (NSF) funded National Center for Engineering and Technology Education (NCETE).

\section{Jared Berrett}

Having obtained a Bachelors of Science degree with a dual major in Psychology and Technology from Brigham Young University, Jared decided to pursue a career in understanding teaching, learning, and technology. He began teaching for three different public high schools in Utah while he finished a Masters degree in Technology Teacher Education. He worked for two major IT corporations and also spent a year as a project management consultant in the IT field before he chose to pursue a $\mathrm{PhD}$ from the University of Illinois Urbana-Champaign. At Illinois, he coordinated an online masters degree program, was an NSF sponsored technology trainee, and consulted with faculty from the College of Engineering and College of Education to improve their teaching and use of technology. He has been involved in numerous projects in industry focusing on topics such as: emotional intelligence, entrepreneurship, and improving and evaluating productivity and the needs of high-tech start-ups. His $\mathrm{PhD}$ is in Education with an emphasis in the psychology of learning and technology. He currently is a faculty member at Brigham Young University in the Technology Teacher Education program where he teaches heavily, consults, serves as the Graduate Coordinator, and mentors numerous graduate and undergraduate students in research projects. He is happily married, has 6 children, and loves to learn. His research interests include technological literacy for a global society of change and advancement, and teaching and learning practices that promote higher order thinking skills and creativity. He is comfortable in all settings of teaching and learning from public classrooms to corporate boardrooms.

\section{Andrew G Swapp}

After retiring from a great career as an Infantry Sergeant in the U.S. Army in 1996, Andy graduated with honors from Southern Utah University with a BS degree in Technology education. He became a Career and Technology education teacher at Milford High School in the Beaver County school district and a small farm owner in the year 2001. He has been innovating a new renewable energy class under the guise of Advanced Technology. He consults on the side for the UPC wind development group.

\section{Thomas L. Erekson}

Dr. Erekson serves as the Dean for the College of Business and Technology at Western Illinois University. Prior to moving to WIU in June 2006, he served as the Director for the School of Technology, a unit in the College of Engineering and Technology at Brigham Young University. He has published more than 60 articles, two books, and has presented more than 100 papers at 
national conferences. Dr. Erekson was instrumental in securing NSF funding for NCETE, a Center for Learning and Teaching. The NCETE's focus is to infuse engineering design and analytical methods into K-12 schools through technology education by linking engineering faculty and technology education faculty at nine leading universities.

\section{Ronald E. Terry}

Ron is a Professor of Chemical Engineering at Brigham Young University and an Associate in BYU's Office of Planning and Assessment. His scholarship centers on pedagogy, student learning, and engineering ethics and has presented/published numerous articles in engineering education. He is one of BYU's co-investigators for the NSF funded NCETE. 